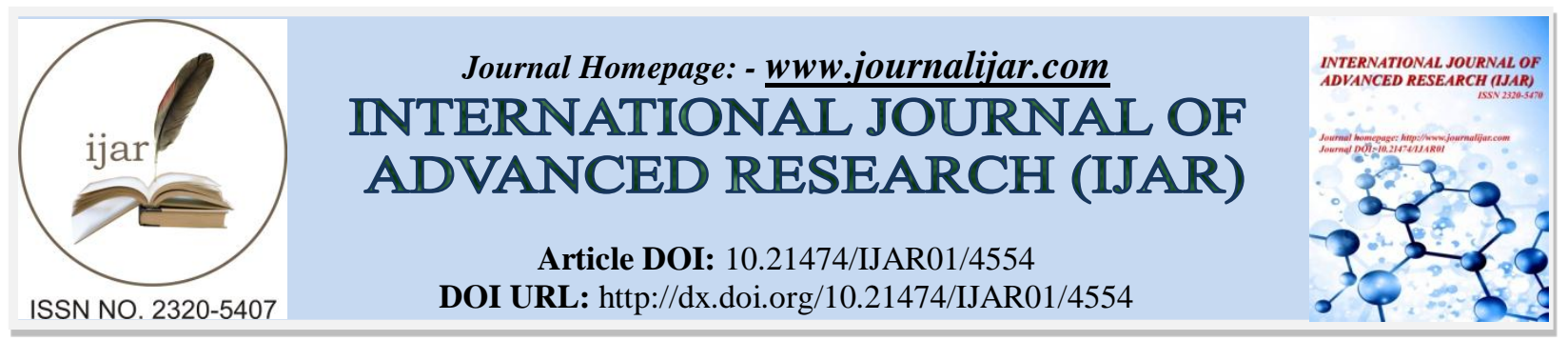

RESEARCH ARTICLE

\title{
STUDY SKILLS IMPROVEMNT THROUGH TRAINING (COUNSELLING) \& ITS EFFECT ACADEMIC PERFORMANCE.
}

\author{
Reshma Khan ${ }^{1}$ and Mukesh Kumar Panth ${ }^{2}$. \\ 1. Research scholar, Deptt. Of Psychology, Dr. H. S. Gour University, Sagar (M.P.), India. \\ 2. Assistant Professor of Psychology, Deptt. Of Psychology, Nehru P. G. College, Lalitpur (U.P.), India.
}

\section{Manuscript Info}

n.........................

Manuscript History

Received: 21 April 2017

Final Accepted: 23 May 2017

Published: June 2017

Key words:-

Study skills, Training (counselling) and Academic performance

\section{Abstract}

Present study aimed to improve the study skills and memory of students through study skill-training program and see the effect on academic performance. Study skill interruption program consisted of 8 sessions, self monitoring motivation enhancement, Time management imbruing concentration, organization of place; thought stopping, memory enhancement \& study methods. The sample consisted of students who are diagnosed as poor in study skill training program regularly at school premises for the period of 8 sessions (twice a week) \& duration of training for each session was approx 1 hour. The subject were administered study skill questionnaire \& Immediate Memory for digits to find out the improvement of study skills on academic performance \& memory capacity of students results reevaluated that the study skill program has improved study skill as academic performance.

Copy Right, IJAR, 2017,. All rights reserved.

\section{Introduction:-}

The task of efficient learning process depends on independent factors such as learning procedures, study skills \& study habits rather than good teaching alone, efficient learning depends on the learners reading skills, writing skills, skills to schedule, time management, good plan to study, efficient method of learning, development of clear thinking, concentration, memory, organization of ideas, underlining, outlining and the adequate skills in examinations, Williamson (1935), Edgar Dale (1969), Berg and Rental (1966) were of the view that students often fail because they do not know how to study and lack of guidance and direction efficient learning involves the proper formation of study habits and study skills.

During examination there is a lot of psychological stress in the students. After the examination when a study is not successful it leads to extreme stress which could even take the form of committing suicide. One reason for high rate of failure in the academic field may be inefficient study skills or poor habit of study. Among failure many students are first generation students coming from low socio economic background. They have neither awareness nor facilities and provisions to cultivate good study skills.

Introduction of study skills programs and learning assistance center will prevent a lot of failures in the examinations. Most students are erroneously under the impression that learning takes place automatically if they listen to the teacher and take notes. Learning demands more effort than the use of acute study skills are those procedure which a learner needs to employ in order to learn efficiently and effectively (Bob Wilson, 1987) study skills are defined as 
those techniques such as summarizing, note taking, outliving or locating material which a learner employ to assist themselves in the efficient learning of the material at hand (The International Encyclopedia of Education 1988). In India, many studies have reported improvement in study skills, improvement in academic performance, reduction in test anxiety etc. by intervention of study skills training. Kanchana, (1986), Ramamurthi and Geethanath (1977), Archana and Aruna (1995), and Rajendran (1998).

Learning styles address the way in which students learn. Flawell states thath "Metacognition refers to ones knowledge concerning one's own cognitive processes or anything related to them eg. the learning relevant properties of information or date" Flawell as cited in Dantonio \& Beisenherg, (2001).

Metacognition refers to higher order thinking which involves active control the cognitive processes engaged in learning in successful learning, it is important to study metacognitive activity and development to determine how students can be taught to better apply their cognitive resources through metacognitive control. Above mentioned can only be done through training intervention (Counselling based).

Reid (2005) stated that the role of metacognition in learning is of great importance as it is related to the learner's awareness of thinking and learning. Tunmer and Chapman (1996) have shown how dyslexic children have poor metacognition awareness that leads to inappropriate learning behavior in reading and spelling.

Finally, several researches highlight the link between metacognition and motivation (Cross \& Paris, 1988; Eisenberg, 2010; Martunez, 2006; Whitebread et al., 2009). Paraphrasing Gredler, Broussard and Garrison define motivation as "the attribute that moves us to do or not to do something" (2004).

\section{Objective Of The Study:-}

The objective of the study is to investigate and improve the study skills and memory of the students and see the effect on academic performance.

\section{Sample:-}

The sample comprised of 25 Ninth class students of Shealing Public School, Chhattarpur (M.P.). The respondent predominantly belonged to middle class families and were diagnosed as poor in study skills. They underment the study skill training intervention regularly at the school premises for a period of 8 sessions, with duration of approx 1 hour. Active participation, home assignment and their own preference of studying methods were made mandatory.

\section{Procedure:-}

Tool and Techniques:-

The following tools were used in the present study:

1. Study skills questionnaire (Kanchana 1985).

2. Immediate memory for digits (Bhatia, 1955).

The participants were briefed individually about the test before administration and the questionnaires were administered to all the subjects before \& after training.

3. Study skills Intervention

The training Intervention on study skill consisted of 8 sessions, which are as follows:-

(a) Self awareness and self (strength \& weaking) and self observations of one's own study behaviour are the first step in changing them.

(b) Motivation Enhancement - Encouragement and uplifting motivation is the pre-requisite and the importance of goal setting was explained to the students.

(c) Organization of place - Study involves active, concentrated participation and a place free from distraction that can contribute greatly to study effectively. The skill of stimulus control were taught to them by asking them to selected a study place with adequate ventilation, sufficient light and minimum distraction, arrangement of books and other study material along with proper sitting furniture.

(d) Time Management - With the help of time chart analysis proper usage of time was taught to the students. Through time chart the students had to look and identify their own time killers like watching T.V., Gossiping, Internet Chatting, Day Time Sleeping, Day Dreaming, Taking much time for eating etc. General principles of planning were given to the students and the time chart was inspected and scheduling was done. 
(e) Improving Concentrations - Note-taking, stimulus control and organization of time were taught to the subjects to facilitate concentration.

(f) Thought stopping - Three methods of stopping disturbing thoughts were taught to the students. They are blocking, substituting and saying 'stop' Autogenic relaxation training was taught to the students to alleviate tension and fatigue during study time and improve concentration.

(g) Memory Enhancement - The need and role of memory in one's life was taught to the students through over learning, periodic reviewing of material, motivated interest, selecting and understanding of the material to be learnt, retrieving the learnt material, using mnemonic devices and index cards.

(h) Study Methods - Making outlines, under lining and the SQ3R method was taught to the students.

\section{Analysis Of Data:-}

Scoring was alone as per the procedure indicated in the manual revision test marks was obtained to assess to academic performance before and after the training. The pre and post test scores of the assessment were analyzed by using't' test.

\section{Result and Discussion:-}

The present study aimed to improve the study skills and memory of the students and see effect on academic performance

Table 1:- 't' value for study skills

\begin{tabular}{|l|l|l|l|}
\hline Assesment & Mean & S.D. & 't' Value \\
\hline Before training & 23 & 6.09 & $12.5^{*}$ \\
\hline After Training & 41.5 & & \\
\hline
\end{tabular}

* P significant at 0.01 level

' $t$ ' value for Academic Performance

\begin{tabular}{|c|c|c|c|}
\hline Assesment & Mean & S.D. & 't' Value \\
\hline Before training & 451.3 & \multirow[t]{2}{*}{4.83} & \multirow[t]{2}{*}{$8.71^{*}$} \\
\hline After Training & 505.25 & & \\
\hline
\end{tabular}

* P significant at 0.01 level

't' value for Immediate Memory spam.

\begin{tabular}{|l|c|c|c|}
\hline Assesment & Mean & S.D. & ' \\
\cline { 1 - 2 } Before training & 10.25 & 1.30 & \multicolumn{2}{|c|}{$4.23^{*}$} \\
\hline After Training & 11.89 & & \\
\hline
\end{tabular}

* P significant at 0.01 level

Table 1, 2 and 3 represent the't' value for study skills, academic performance and immediate memory span. The results of the present study reveals that the study skills training program has improved metacognitive level of the students i.e. study skills improvement as well as the level of memory of the students, which is turn enhanced the academic performance. This finding has been supported by many earlier studies conducted by R. Rajendran 1998, Kanchana 1986, Archana and Aruna, Barnett 1951, Bamman 1954)

This gives an insight that those students with poor study skills have benefited and if the same training is given to other students their academic performance can also be enriched. Thus, it can be said that the study skills training is quite effective in improving academic performance of students. 


\section{Rferences:-}

1. Bhatia, C.M. (1955). Performance test of Intelligence Under Indian Conditions. Bombay, Oxford University Press.

2. Bichler, F. and Snouman J. (1993). Psychology applied to teaching. Ithed. New Jersey U.S.A. Houghton Mifflin Comany.

3. Dentonio, M. \& Beisonherz, P.C. (2001). Learning to question, question to learn : Developing effective teachers questioning practices, Boston; London; Allyn and Bacon.

4. Kanchana M. (1986). Effect of behavior modification technique in reducing test anxiety and improving academic achievement of high school girls, University of Madras Chennai.

5. Rajendran R. (1998). Improving Academic Excellence through personality development program among higher secondary students. Indian Journal of Addled Psychology.

6. Ramamurti P.V. and Geethanath, P.S. (1979). A study skill inventory for high school and junior college level in Telgu Journal of Psychological Research.

7. Ray, K. \& Smith, M. C. (2010). The kindergarten child: What teachers and administrators need to know to promote academic success in all children. Early childhood education journal.

8. Reid, G. (2005). Dyslexia, metacognition and learning styles. University of Edinburgh, Scotland. Retrieved on August 21, 2006 from http://www.gavinreid.co.uk.

9. Singh, Archana and Brooto, Aruna (1995). Effect of study skills counseling on high test anxiety students. Journal of Psychological Researches.

10. Wilson Bob (1987). Methods of training: Resource-based and open learning: study skills. 